\title{
Estimação da evapotranspiração de referência no Estado do Rio de Janeiro usando redes neurais artificiais
}

\author{
Sidney S. Zanetti ${ }^{1}$, Elias F. Sousa ${ }^{1}$, Daniel F. de Carvalho ${ }^{2} \&$ Salassier Bernardo ${ }^{1}$
}

\begin{abstract}
RESUMO
Propor uma rede neural artificial (RNA) para estimar a evapotranspiração de referência (ETo) em função das coordenadas de posição geográfica e da temperatura do ar no Estado do Rio de Janeiro, motivou a realização do presente estudo. Os dados utilizados no treinamento da rede foram obtidos de 17 séries históricas de elementos climáticos localizadas nesse Estado. A ETo diária calculada pelo método de Penman-Monteith (FAO-56) foi utilizada como referência para treinar as redes. As RNAs, do tipo perceptron de múltiplas camadas, foram treinadas para estimar a ETo em função da latitude, longitude, altitude, temperatura média do ar, amplitude térmica diária e dia do ano. Após o treinamento com várias configurações de rede, selecionou-se a que apresentou o melhor desempenho, a qual é composta de apenas uma camada intermediária (com vinte neurônios e função de ativação do tipo sigmóide logística) e uma camada de saída (com um neurônio e função de ativação linear). Pelos resultados obtidos conclui-se que, levando-se em consideração apenas as coordenadas de posição geográfica e a temperatura do ar, pode-se estimar a ETo (valores diários) em 17 localidades do Estado do Rio de Janeiro usando uma RNA.
\end{abstract}

Palavras-chave: elementos climáticos, inteligência artificial, modelos empíricos

\section{Reference evapotranspiration estimate in Rio de Janeiro State using artificial neural networks}

\begin{abstract}
This work was performed with the aim of proposing an artificial neural network (ANN) to estimate the reference evapotranspiration (ETo) as a function of geographic position coordinates and air temperature in the State of Rio de Janeiro. Data used for the network training were collected from 17 historical time series of climatic elements located in the State of Rio de Janeiro. The daily ETo calculated by Penman-Monteith (FAO-56) method was used as a reference for network training. ANNs of multilayer perceptron type were trained to estimate ETo as a function of latitude, longitude, altitude, mean air temperature, thermal daily amplitude and day of the year. After training with different network configurations, the one showing best performance was selected, and was composed by only one intermediary layer (with twenty neurons and sigmoid logistic activation function) and one output layer (with one neuron and linear activation function). According to the results obtained it can be concluded that, considering only geographical positioning coordinates and air temperature, it is possible to estimate daily ETo in 17 places of Rio de Janeiro State by using an ANN.
\end{abstract}

Key words: climatic elements, artificial intelligence, empirical modeling

LEAG/UENF. Av. Alberto Lamego 2000, Parque Califórnia, CEP 28013-602, Campos dos Goytacazes, RJ. Fone: (22) 2726-1543. E-mails: ssz@bol.com.br; efs@uenf.br; salassie@uenf.br

2 DE/IT/UFRRJ. BR 465, km 7, CEP 23851-970, Seropédica, RJ. E-mail: carvalho@ufrrj.br. Bolsista do CNPq 


\section{INTRODUÇÃO}

As redes neurais artificiais (RNAs) são sistemas paralelos distribuídos, compostos de unidades simples de processamento, que calculam determinadas funções matemáticas. Tais unidades são dispostas em uma ou mais camadas e interligadas por um grande número de conexões. Na maioria dos modelos, essas conexões estão associadas a pesos os quais, após o processo de aprendizagem, armazenam o conhecimento adquirido pela rede. O funcionamento dessas redes é inspirado em uma estrutura biológica concebida pela natureza: o cérebro humano (Braga et al., 2000; Haykin, 2001; Kovács, 2002).

As RNAs têm sido utilizadas com sucesso para modelar relações envolvendo séries temporais complexas em várias áreas do conhecimento. Segundo Galvão et al. (1999), em função de sua estrutura não-linear as RNAs conseguem captar características mais complexas dos dados, o que nem sempre é possível com a utilização das técnicas estatísticas tradicionais. Para Sudheer et al. (2003), a maior vantagem das RNAs sobre os métodos convencionais é que elas não requerem informação detalhada sobre os processo físicos do sistema a ser modelado, sendo este descrito explicitamente na forma matemática (modelo de entrada-saída).

A evapotranspiração é um fenômeno complexo e não-linear, pois depende da interação entre os vários elementos climáticos (radiação solar, velocidade do vento, temperatura e umidade do ar) e do tipo e estádio de crescimento da cultura (Kumar et al., 2002). De acordo com Pereira et al. (2002), a escolha de um método para se estimar a evapotranspiração depende de uma série de fatores, em que um deles é a disponibilidade de dados meteorológicos, visto que os métodos mais complexos que exigem grande número de variáveis somente têm aplicabilidade quando há disponibilidade de todos os dados necessários. Quando existem dados disponíveis, Allen et al. (1998) recomendam a utilização do método de Penman-Monteith (FAO-56) como padrão para o cálculo da evapotranspiração de referência (ETo); todavia, as variáveis meteorológicas necessárias para aplicação do método de Penman-Monteith nem sempre se encontram disponíveis, particularmente as relacionadas à solução do termo aerodinâmico (velocidade do vento e déficit de pressão do vapor d’água no ar); desta forma, tornam-se importantes os métodos para estimar a ETo em função de elementos climáticos que podem ser obtidos de maneira mais prática como, por exemplo, a temperatura do ar e a radiação solar extraterrestre (Hargreaves \& Samani, 1985; Samani, 2000).

Vários autores realizaram estudos utilizando RNAs com a finalidade de estimar a evapotranspiração em função de elementos climáticos (Arca et al., 2001; Odhiambo et al., 2001; Kumar et al., 2002; Silva, 2002; Sudheer et al., 2003; Trajkovic et al., 2003; Zanetti et al., 2007), sendo que todos encontraram resultados satisfatórios, inclusive melhores que os obtidos com o método convencional de Penman-Monteith (Kumar et al., 2002).

Embora tenham conseguido bons resultados, os autores que utilizaram RNAs para estimar a ETo, com exceção de Arca et al. (2001), Sudheer et al. (2003) e Zanetti et al. (2007), não se empenharam em simplificar as variáveis de entrada utili- zando, em vários trabalhos, os mesmos dados climáticos requeridos para aplicação do método de Penman-Monteith.

Arca et al. (2001) testaram onze combinações dos seguintes dados de entrada: ETo estimada pelos métodos de Hargreaves, Hargreaves-Samani e Blaney-Criddle, déficit de saturação de vapor, velocidade do vento, radiação solar extraterrestre e temperatura do ar. Na combinação mais simplificada a ETo foi estimada em função de duas variáveis: radiação solar extraterrestre e temperatura do ar.

Sudheer et al. (2003) utilizaram três opções de dados de entrada para estimar a ETo a partir de dados de temperatura média do ar, umidade relativa, velocidade do vento e duração do brilho solar, porém com uma série de dados restrita a poucos dias do ano; na opção mais simplificada, a ETo foi estimada em função apenas da temperatura média do ar e da data correspondente à sua ocorrência. Resultados satisfatórios foram obtidos na estimação da ETo usando-se RNAs associadas com poucos dados de entrada, entretanto, os autores ressaltam a necessidade de se realizar outros estudos utilizando maior número de dados visando reforçar as conclusões obtidas.

Zanetti et al. (2007) desenvolveram e testaram uma rede neural artificial para estimar a ETo em função das temperaturas máxima e mínima do ar em Campos dos Goytacazes, RJ. Apesar dos resultados satisfatórios, a rede apresentou baixo potencial para aplicação em locais diferentes daquele em que foi desenvolvida. Os referidos autores sugerem que esta limitação pode ser contornada usando-se dados de vários locais e se considerando as suas coordenadas geográficas no processo de treinamento da RNA, possibilitando que haja assimilação da influência da variação espacial no processo de estimação da evapotranspiração.

Apesar da existência de alguns trabalhos visando simplificar os dados de entrada destinados à estimação da ETo, percebe-se que ainda há outras opções a serem estudadas no que se refere à utilização de dados climáticos limitados. O presente trabalho foi motivado pela possibilidade de tais estudos resultarem em modelos mais eficientes que os até então apresentados na literatura.

Nesse contexto e diante da importância da evapotranspiração no manejo da irrigação e na modelagem hidrológica, realizou-se este trabalho com o objetivo de propor uma RNA visando estimar a evapotranspiração de referência em função das temperaturas máxima e mínima do ar, para o Estado do Rio de Janeiro, levando-se em consideração a posição geográfica das estações meteorológicas utilizadas.

\section{MATERIAL E MÉTODOS}

Neste estudo foram utilizadas 17 séries históricas de elementos climáticos compreendidas entre 1961 e 1978; tais séries foram obtidas de estações meteorológicas do INMET, localizadas no Estado do Rio de Janeiro (Tabela 1 e Figura 1), cujos dados utilizados foram: temperatura do ar (máxima e mínima); umidade relativa do ar (máxima e mínima); insolação e velocidade do vento, a partir dos quais se calculou a ETo diária pelo método de Penman-Monteith (FAO-56) (Allen et al., 1998). 
Tabela 1. Estações meteorológicas utilizadas na estimação da evapotranspiração de referência, no Estado do Rio de Janeiro

\begin{tabular}{|c|c|c|c|c|c|c|}
\hline Estação & Nome & Código & $\begin{array}{l}\text { Latitude } \\
\text { (Sul) }\end{array}$ & $\begin{array}{c}\text { Longitude } \\
\text { (Oeste) }\end{array}$ & $\begin{array}{l}\text { Altitude } \\
\text { (m) }\end{array}$ & $\begin{array}{l}\mathrm{N}^{0} \text {. de anos } \\
\text { de registro }\end{array}$ \\
\hline 1 & Angra dos Reis 83788 & 02344013 & $23^{\circ} 04^{\prime} 00^{\prime \prime}$ & $44^{0} 19^{\prime} 00^{\prime \prime}$ & 2 & 12,8 \\
\hline 2 & Bangu 83790 & 02243141 & $22^{\circ} 52^{\prime} 00^{\prime \prime}$ & $43^{\circ} 27^{\prime} 00^{\prime \prime}$ & 40 & 7,5 \\
\hline 2 & Barreirinha 83752 & 02244017 & $22^{\circ} 27^{\prime} 00^{\prime \prime}$ & $44^{\circ} 50^{\prime} 00^{\prime \prime}$ & 757 & 14,1 \\
\hline 4 & Cabo Frio 83747 & 02242066 & $22^{\circ} 53^{\prime} 00^{\prime \prime}$ & $42^{\circ} 01^{\prime} 00^{\prime \prime}$ & 3 & 7,6 \\
\hline 5 & Campos 83698 & 02141044 & $21^{\circ} 45^{\prime} 00^{\prime \prime}$ & $41^{\circ} 20^{\prime} 00^{\prime \prime}$ & 11 & 17,9 \\
\hline 6 & Ecologia Agric. (km 47) 83741 & 02243186 & $22^{\circ} 46^{\prime} 00^{\prime \prime}$ & $43^{\circ} 41^{\prime} 00^{\prime \prime}$ & 33 & 17,2 \\
\hline 7 & Ilha Guaíba 83758 & 02344017 & $23^{\circ} 01^{\prime} 00^{\prime \prime}$ & $44^{\circ} 02^{\prime} 00^{\prime \prime}$ & 64 & 7,0 \\
\hline 8 & Itaperuna 83695 & 02141045 & $21^{\circ} 12^{\prime} 00^{\prime \prime}$ & $41^{\circ} 54^{\prime} 00^{\prime \prime}$ & 124 & 10,2 \\
\hline 9 & Nova Friburgo 83745 & 02242070 & $22^{\circ} 17^{\prime} 00^{\prime \prime}$ & $42^{\circ} 32^{\prime} 00^{\prime \prime}$ & 857 & 11,3 \\
\hline 10 & Núcleo Colonial São Bento 83802 & 02243157 & $22^{\circ} 44^{\prime} 00^{\prime \prime}$ & $43^{\circ} 18^{\prime} 00^{\prime \prime}$ & 6 & 16,1 \\
\hline 11 & Pinheiral 83754 & 02244093 & $22^{\circ} 31^{\prime} 00^{\prime \prime}$ & $44^{\circ} 00^{\prime} 00^{\prime \prime}$ & 385 & 13,0 \\
\hline 12 & Piraí 83757 & 02243165 & $22^{\circ} 38^{\prime} 00^{\prime \prime}$ & $43^{\circ} 53^{\prime} 00^{\prime \prime}$ & 388 & 7,6 \\
\hline 13 & Praça XV/Aterro Flamengo 83743 & 02243129 & $22^{\circ} 54^{\prime} 00^{\prime \prime}$ & $43^{\circ} 10^{\prime} 00^{\prime \prime}$ & 5 & 18,0 \\
\hline 14 & Resende 83738 & 02244092 & $22^{\circ} 29^{\prime} 00^{\prime \prime}$ & $44^{\circ} 26^{\prime} 43^{\prime \prime}$ & 440 & 18,0 \\
\hline 15 & Santa Maria Madalena 83696 & 02142051 & $21^{\circ} 57^{\prime} 00^{\prime \prime}$ & $42^{\circ} 01^{\prime} 00^{\prime \prime}$ & 620 & 16,0 \\
\hline 16 & Teresópolis (Parque Nac.) 83806 & 02242071 & $22^{\circ} 26^{\prime} 00^{\prime \prime}$ & $42^{\circ} 59^{\prime} 00^{\prime \prime}$ & 959 & 16,7 \\
\hline 17 & Vassouras 83742 & 02243151 & $22^{\circ} 25^{\prime} 00^{\prime \prime}$ & $43^{\circ} 40^{\prime} 00^{\prime \prime}$ & 437 & 16,2 \\
\hline
\end{tabular}

1 - Angra dos Reis 83788

2 - Bangu 83790

3 - Barreirinha 83752

4 - Cabo Frio 83747

5 - Campos 83698

6 - Ecologia Agric. (Km 47) 83741

7 - Ilha Guaíba 83758

8 - Itaperuna 83695

9 - Nova Friburgo 83745
10 - Núcleo colonial São Bento 83802

11 - Pinheiral 83754

12 - Piraí 83757

13 - Praça XV/Aterro Flamengo 83743

14 - Resende 83738

15 - Santa Maria Madalena 83696

16 - Teresópolis (Parque Nac.) 83803

17 - Vassouras 83742

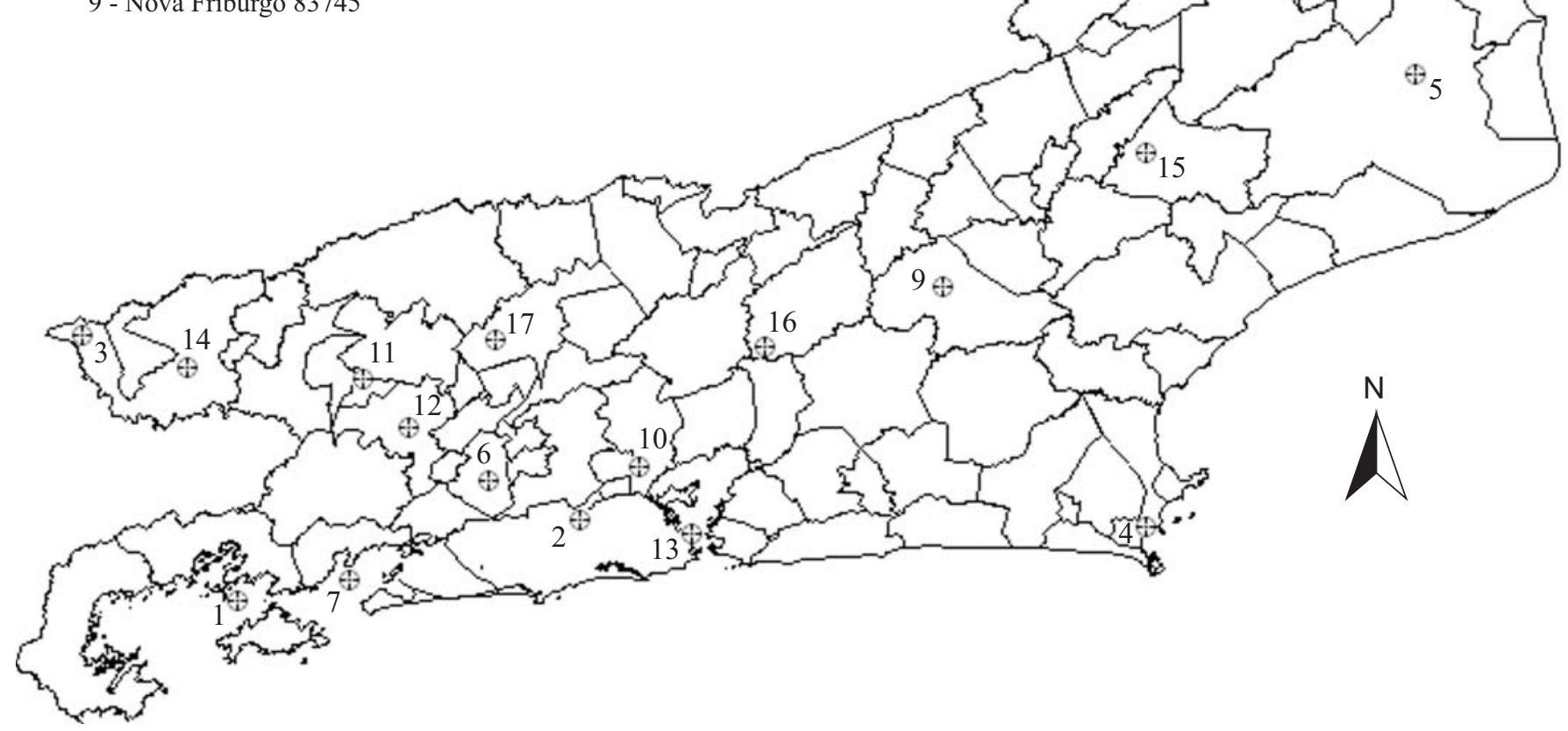

Figura 1. Distribuição espacial das estações meteorológicas utilizadas na estimação da evapotranspiração de referência, no Estado do Rio de Janeiro

Na obtenção do modelo para estimar a ETo, projetou-se uma rede neural através das seguintes variáveis de entrada: latitude, longitude, altitude, temperatura média do ar, amplitude térmica diária e o dia seqüencial do ano. A temperatura média do ar e a amplitude térmica foram obtidas a partir da média aritmética e da diferença entre as temperaturas máxima e mínima do ar, respectivamente; portanto, o modelo proposto demanda somente dados diários das temperaturas máxima e mínima do ar para estimar a ETo, já que as demais variáveis são características espaciais e temporais facilmente obtidas.

O fato de terem sido inseridas, na RNA, as coordenadas 
geográficas de cada estação, está relacionado à intenção de se obter um modelo apto para fazer extrapolações espaciais.

Os dados diários das 17 estações foram agrupados em linhas e armazenados em um arquivo texto, obtendo-se um conjunto com 83.806 observações diárias; deste, foram derivados dois subconjuntos: o primeiro, com 70.000 observações, serviu para treinar a rede e o segundo, com 13.806 observações, foi utilizado para testar o seu desempenho. As linhas do arquivo contendo os dados de treinamento foram submetidas a uma aleatorização visando eliminar qualquer influência do ordenamento dos dados no referido processo.

\section{Características da rede neural artificial utilizada}

Utilizou-se uma RNA do tipo perceptron de múltiplas camadas (MLP, multilayer perceptron); nesse tipo de rede o sinal de entrada se propaga para frente (feedforward), camada por camada, sendo em seguida retropropagado para a correção do erro (ajuste dos pesos sinápticos); este procedimento é repetido durante várias iterações até a finalização do treinamento.

Todos os neurônios presentes na RNA utilizada foram configurados com base no modelo apresentado por Haykin (2001), conforme ilustrado na Figura 2; nos pesos sinápti$\cos \left(\mathrm{w}_{\mathrm{k}, \mathrm{j}}\right)$ o índice k se refere ao neurônio em questão, enquanto o índice j diz respeito ao sinal de entrada da sinapse com a qual o peso tem relação.

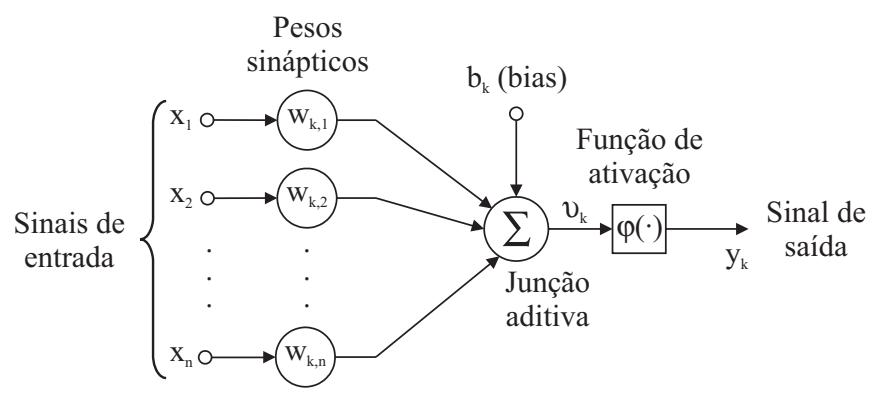

Figura 2. Modelo não-linear dos neurônios utilizados na rede neural artificial

A junção aditiva possui o propósito de somar todos os sinais de entrada $\left(\mathrm{x}_{\mathrm{j}}\right)$ ponderados pelos pesos sinápticos de cada neurônio. O bias funciona aumentando ou diminuindo a influência do valor da entrada líquida para a ativação do neurônio; já a função de ativação funciona restringindo a amplitude de saída de determinado neurônio e adicionando não-linearidade ao modelo; matematicamente, o neurônio apresentado na Figura 2 pode ser descrito pelas seguintes equações:

$$
\begin{gathered}
u_{k}=\sum_{j=1}^{n} w_{k, j} \cdot x_{j} \\
v_{k}=u_{k}+b_{k} \\
y_{k}=\varphi\left(v_{k}\right)
\end{gathered}
$$

em que $\mathrm{u}_{\mathrm{k}}$ é a saída do combinador linear (junção aditiva); $\mathrm{w}_{(\mathrm{k}, 1)}, \mathrm{w}_{(\mathrm{k}, 2)}, \ldots, \mathrm{w}_{(\mathrm{k}, \mathrm{n})}$ são os pesos sinápticos; $\mathrm{x}_{1}, \mathrm{x}_{2}, \ldots \mathrm{x}_{\mathrm{n}}$ são os sinais de entrada; $v_{\mathrm{k}}$ é o potencial de ativação; b é o bias; $\mathrm{y}_{\mathrm{k}}$ é o sinal de saída do neurônio $\mathrm{k}$ e $\varphi(\cdot)$ é a função de ativação. No neurônio de saída da rede a ETo corresponde ao seu respectivo sinal $\mathrm{y}_{\mathrm{k}}$.

A RNA foi treinada de forma supervisionada com o algoritmo de Levenberg-Marquardt, o qual utiliza, para aproximação do mínimo da função de erro (Eq. 4), o método de Newton (Hagan \& Menhaj, 1994). Tal algoritmo foi selecionado devido à sua superioridade em relação aos outros algoritmos mais comumente utilizados (p.ex. back-propagation), conforme relatado por Soares \& Nadal (1999), de acordo com os quais, embora o algoritmo de Levenberg-Marquardt demande maior tempo de processamento que o back-propagation, para cada iteração de treinamento, a sua rápida convergência diminui sensivelmente não só o número total de iterações necessárias ao treinamento mas, também, o tempo de processamento. O erro quadrado médio - EQM $\left(\mathrm{mm} \mathrm{d}^{-1}\right)^{2}$, foi obtido segundo a expressão:

$$
\mathrm{EQM}=\frac{\sum_{\mathrm{i}=1}^{\mathrm{n}}\left(\mathrm{Yo}_{0}-\mathrm{Ye}^{2}\right.}{\mathrm{n}}
$$

em que: $\mathrm{n}$ - número de observações; Yo - ETo estimada pelo método de Penman-Monteith, $\mathrm{mm} \mathrm{d}^{-1}$; Ye - ETo estimada pela rede neural artificial, $\mathrm{mm} \mathrm{d}^{-1}$

Utilizou-se, como critério para encerrar o treinamento, o método de treinamento com parada antecipada (Haykin, 2001), com o qual foi possível identificar o início do excesso de treinamento através do uso da validação cruzada; para tanto, os dados de treinamento foram subdivididos em outros dois subconjuntos: um de estimação e outro de validação; o subconjunto de estimação foi utilizado para treinar a rede sendo que, após cada iteração, a seção de treinamento era interrompida, visando realizar a validação cruzada. Enquanto o EQM do subconjunto de validação se apresentava menor que seu valor nas iterações anteriores, o treinamento da rede era continuado; caso contrário, o treinamento era finalizado uma vez que, segundo Haykin (2001), o que a rede aprende após esse ponto é essencialmente ruído contido nos dados de treinamento, ocasionando perda na habilidade de generalização entre padrões de entrada-saída similares.

Visando selecionar uma RNA que proporcionasse o melhor desempenho, fez-se um estudo prévio no qual foram realizados vários testes, variando-se o número de camadas intermediárias, o número de neurônios e a função de ativação nas camadas. Para cada combinação dessas características a rede foi treinada e testada possibilitando a escolha da melhor RNA para estimar a ETo. A camada de saída da rede foi predefinida com apenas um neurônio e função de ativação do tipo linear.

\section{Avaliação dos resultados}

Após o processo de treinamento da RNA e se utilizando o conjunto de dados destinado para teste da mesma (13.806 observações), os valores de ETo foram estimados com a rede neural e comparados com os valores de ETo calculados pelos métodos de Penman-Monteith e pelo de Hargreaves. 
Realizou-se, para cada estação, uma regressão linear simples $\left(Y=\beta_{0}+\beta_{1} \cdot X\right)$, sendo considerados, como variáveis dependentes, os valores de ETo calculados pelo método de Penman-Monteith e, como variáveis independentes, os valores de ETo estimados com a rede neural e pelo método de Hargreaves; os resultados foram analisados por meio dos parâmetros $\left(\beta_{0}\right.$ e $\left.\beta_{1}\right)$ das equações e pelo coeficiente de determinação $\left(r^{2}\right)$ das regressões, enquanto o teste " $t$ " foi utilizado para se avaliar estatisticamente o valor do intercepto (Ho: $\left.\beta_{o}=0\right)$ e da inclinação da reta $\left(\right.$ Ho: $\left.\beta_{1}=1\right)$, em nível de $1 \%$ de probabilidade.

Adicionalmente e visando quantificar o grau de ajustamento entre os valores observados e estimados, calculouse o índice de desempenho (c) proposto por Camargo \& Sentelhas (1997), o qual é resultante da multiplicação entre o índice de concordância proposto por Willmott (1981) e o coeficiente de correlação de Pearson; o índice c é um valor adimensional variando entre 0 e 1 , sendo que o valor 1 representa o completo ajustamento enquanto o valor 0 indica o oposto.

\section{RESULTADOS E DISCUSSÃO}

A RNA escolhida, isto é, a que apresentou melhor desempenho com a mínima configuração possível, se constitui de uma camada de entrada (com seis variáveis), uma camada intermediária (com vinte neurônios) e uma camada de saída (com um neurônio) conforme a Figura 3. O fato da rede escolhida, que apresentou melhor desempenho, ter apenas uma camada intermediária, está de acordo com os resultados encontrados por Kumar et al. (2002), pois esses autores também concluíram que uma RNA com apenas uma camada intermediária é suficiente para representar a relação não-linear entre os elementos climáticos e a correspondente ETo.

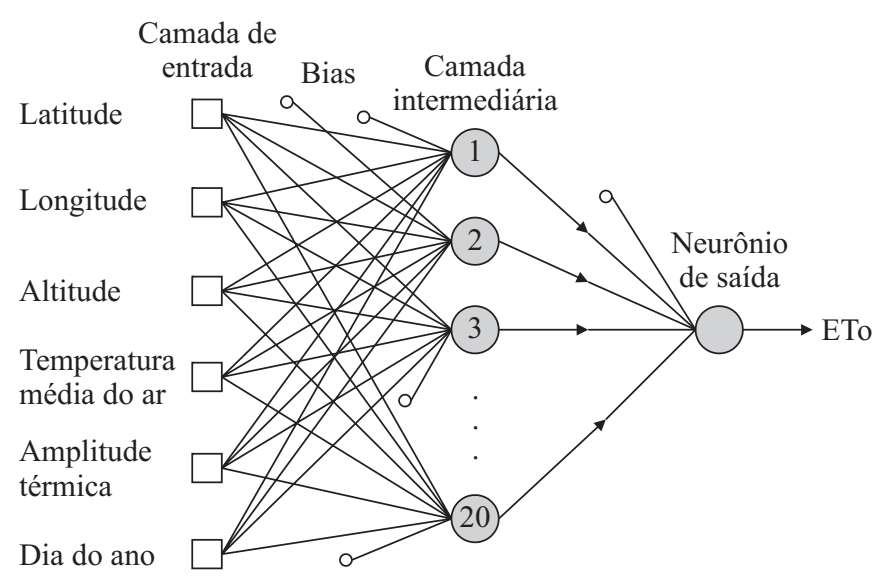

Figura 3. Diagrama em blocos demonstrando a arquitetura da rede neural utilizada com apenas uma camada intermediária

Para os neurônios da camada intermediária foi adotada a função de ativação sigmóide logística (Eq. 5); trata-se de uma das funções propostas por Demuth \& Beale (2003); tal fun- ção foi selecionada por haver proporcionado os melhores resultados, qual seja:

$$
\varphi(v)=\frac{2}{1+\exp (-2 . v)}-1
$$

Apresentam-se, na Tabela 2, os indicadores estatísticos do ajuste entre os valores de ETo calculados pelo método de Penman-Monteith e os estimados pela rede neural artificial para cada uma das 17 estações meteorológicas consideradas.

Tabela 2. Indicadores estatísticos do ajuste entre os valores de ETo estimada por Penman-Monteith e ETo estimada pela rede neural

\begin{tabular}{ccccccc}
\hline Estação & $\boldsymbol{\beta}_{\mathbf{0}}$ & $\boldsymbol{\beta}_{1}$ & $\mathbf{r}^{2}$ & $\mathbf{n}$ & $\begin{array}{c}\text { EQM } \\
\left(\mathbf{m m ~ d}^{-1}\right)^{2}\end{array}$ & $\mathbf{c}$ \\
1 & $-0,013$ & 1,004 & 0,7289 & 704 & 0,4 & 0,782 \\
2 & 0,247 & 0,925 & 0,7548 & 441 & 0,5 & 0,808 \\
3 & 0,028 & 0,999 & 0,8222 & 812 & 0,4 & 0,861 \\
4 & $-0,085$ & 1,019 & 0,6176 & 451 & 0,6 & 0,682 \\
5 & $-0,150$ & 1,033 & 0,7111 & 1053 & 0,9 & 0,765 \\
6 & $-0,066$ & 1,030 & 0,7633 & 1025 & 0,9 & 0,810 \\
7 & $-0,073$ & 1,016 & 0,6243 & 378 & 1,2 & 0,689 \\
8 & $-0,093$ & 1,016 & 0,7799 & 591 & 0,5 & 0,825 \\
9 & 0,207 & 0,930 & 0,6363 & 666 & 0,4 & 0,706 \\
10 & $-0,092$ & 1,026 & 0,8061 & 922 & 0,4 & 0,846 \\
11 & $-0,019$ & 1,018 & 0,7970 & 773 & 0,4 & 0,839 \\
12 & $-0,011$ & 0,989 & 0,7573 & 398 & 0,4 & 0,807 \\
13 & $-0,155$ & 1,025 & 0,6324 & 1047 & 0,8 & 0,696 \\
14 & $-0,196$ & 1,046 & 0,6125 & 1104 & 0,9 & 0,675 \\
15 & $-0,041$ & 1,018 & 0,8240 & 939 & 0,3 & 0,861 \\
16 & $-0,024$ & 1,002 & 0,8466 & 985 & 0,2 & 0,880 \\
17 & 0,111 & 0,966 & 0,6852 & 954 & 0,7 & 0,747 \\
\hline
\end{tabular}

Os parâmetros $\beta_{0}$ e $\beta_{1}$, obtidos para ambas as localidades, não diferiram estatisticamente de 0 e 1 , respectivamente, permitindo inferir que a ETo estimada pela rede neural não diferiu estatisticamente da ETo calculada pelo método de Penman-Monteith.

A qualidade do ajuste pode ser confirmada ainda pelos altos valores do índice de desempenho (c). Para as diferentes localidades o desempenho variou entre "Bom” $(c=0,675)$ e "Ótimo” (c = 0,880), de acordo com o critério de interpretação proposto por Camargo \& Sentelhas (1997).

Tem-se, na Tabela 3, os indicadores estatísticos do ajuste entre os valores de ETo calculados pelo método de PenmanMonteith e os calculados pelo método de Hargreaves para cada uma das 17 estações meteorológicas consideradas.

Os parâmetros $\beta_{\text {o }}$ e $\beta_{1}$ apresentaram, neste caso, magnitude variável em função da localidade testada; os parâmetros $\beta_{0}$ não diferiram estatisticamente de 0 em 11 localidades, nem os parâmetros $\beta_{1}$ de 1 em apenas 7 localidades.

Para as diferentes localidades o método de Hargreaves apresentou índice de desempenho variando entre "Sofrível” 
Tabela 3. Indicadores estatísticos do ajuste entre os valores de ETo estimada pelo método de Penman-Monteith e pelo método de Hargreaves

\begin{tabular}{|c|c|c|c|c|c|c|}
\hline Estação & $\beta_{0}^{a}$ & $\beta_{1}^{b}$ & $r^{2}$ & n & $\begin{array}{c}\text { EQM } \\
\left(\mathrm{mm} \mathrm{d}^{-1}\right)^{2}\end{array}$ & C \\
\hline 1 & $-0,234$ ns & 0,930 ns & 0,7040 & 704 & 0,7 & 0,735 \\
\hline 2 & $-0,096$ ns & $0,819 * *$ & 0,7173 & 441 & 1,3 & 0,712 \\
\hline 3 & $-0,105^{\mathrm{ns}}$ & 0,984 ns & 0,7120 & 812 & 0,7 & 0,767 \\
\hline 4 & $0,139 \mathrm{~ns}$ & $1,083^{\mathrm{ns}}$ & 0,5789 & 451 & 0,9 & 0,617 \\
\hline 5 & $-0,752^{\star \star}$ & $1,169 * \star$ & 0,6740 & 1053 & 1,1 & 0,718 \\
\hline 6 & $-0,583^{* *}$ & 1,160 ** & 0,6923 & 1025 & 1,3 & 0,736 \\
\hline 7 & $0,515^{\mathrm{ns}}$ & $0,980^{\mathrm{ns}}$ & 0,4515 & 378 & 2,0 & 0,517 \\
\hline 8 & $-0,499 * *$ & $0,982 \mathrm{~ns}$ & 0,7715 & 591 & 0,9 & 0,787 \\
\hline 9 & $0,088 \mathrm{~ns}$ & 0,671 ** & 0,6065 & 666 & 1,9 & 0,556 \\
\hline 10 & $-0,365^{\star \star}$ & $0,861^{* *}$ & 0,7866 & 922 & 1,4 & 0,749 \\
\hline 11 & $-0,189 \mathrm{~ns}$ & $0,811^{\star *}$ & 0,7484 & 773 & 1,5 & 0,712 \\
\hline 12 & $-0,154$ ns & $0,795^{\star *}$ & 0,7365 & 398 & 1,5 & 0,704 \\
\hline 13 & $0,511 * *$ & 0,984 ns & 0,5875 & 1047 & 1,1 & 0,639 \\
\hline 14 & $-0,056^{\mathrm{ns}}$ & $0,821^{* *}$ & 0,5637 & 1104 & 1,7 & 0,601 \\
\hline 15 & $-0,266^{\star *}$ & $0,860 * *$ & 0,8078 & 939 & 0,9 & 0,769 \\
\hline 16 & $-0,129 \mathrm{~ns}$ & 0,771 ** & 0,8323 & 985 & 1,2 & 0,740 \\
\hline 17 & $-0,228 \mathrm{~ns}$ & $0,922^{\mathrm{ns}}$ & 0,6359 & 954 & 1,1 & 0,680 \\
\hline
\end{tabular}

a/** e ns: significativo e não-significativo em nível de $1 \%$ de probabilidade pelo teste $t$ respectivamente ( $\left.\mathrm{Ho}: \beta_{0}=0\right)$

$\mathrm{b} /{ }^{* *}$ e ns: significativo e não-significativo em nível de $1 \%$ de probabilidade pelo teste $\mathrm{t}$, respectivamente $\left(\mathrm{Ho}: \beta_{1}=1\right)$

(c=0,517) e "Muito Bom" (c=0,787), de acordo com a classificação proposta por Camargo \& Sentelhas (1997).

Observa-se, comparando-se os resultados das Tabelas 2 e 3 , que o modelo baseado na RNA foi mais eficiente que o método de Hargreaves para estimar a ETo, possibilitando melhor desempenho ao realizar extrapolações temporais nas 17 localidades testadas.

Em geral, as RNAs necessitam de muitos dados para um treinamento eficiente e, em assim sendo, é provável que a rede desenvolvida não tenha assimilado adequadamente a influência da variação espacial na estimação da evapotranspiração de referência; portanto, mesmo se considerando as coordenadas de posição geográfica das estações no treinamento da rede, sua capacidade de realizar extrapolações espaciais ficou prejudicada em virtude do reduzido número de estações utilizadas.

Do ponto de vista prático, e com base no trabalho desenvolvido por Zanetti et al. (2007), a grande vantagem do método proposto no presente estudo (rede neural artificial) está na utilização de registros diários das temperaturas máxima e mínima do ar, fato que possibilita estimar a ETo com a simples utilização de um termômetro de máxima e de mínima.

\section{CONCLUSÕES}

1. Nas 17 localidades do Estado do Rio de Janeiro consideradas no presente estudo, a evapotranspiração de referência pode ser estimada com segurança utilizando-se redes neurais artificiais, a partir de dados de temperaturas máxima e mínima do ar e das coordenadas de posição geográfica do local (latitude, longitude e altitude).

\section{LITERATURA CITADA}

Allen, R. G.; Pereira, L. S.; Raes, D.; Smith, M. Crop evapotranspiration - guidelines for computing crop water requirements. Rome: FAO, 1998. 300p. FAO Irrigation and Drainage Paper 56

Arca, B.; Beniscasa, F.; Vincenzi, M. Evaluation of neural network techniques for estimating evapotranspiration; National Research Council. http://server.ss.ibimet. cnr.it/ arca1/papers/ Evaluation\%20of\%20neural\%20network\%20techniques\%20 for\%20estimating\%20evapotranspiration_EANN_2001.PDF. 22 Jul. 2001.

Braga, A. P.; Ludemir, T. B.; Carvalho, A. C. P. L. F. Redes neurais artificiais: Teoria e aplicações. Rio de Janeiro: LTC, 2000. 262p.

Camargo, A. P.; Sentelhas, P. C. Avaliação do desempenho de diferentes métodos de estimativa da evapotranspiração potencial no Estado de São Paulo, Brasil. Revista Brasileira de Agrometeorologia, v.5, n.1, p.89-97, 1997.

Demuth, H.; Beale, M. Neural network toolbox: For use with MATLAB. User's Guide Version 4.0, Natick: The Math Works, 2003.

Galvão, C. O.; Valença, M. J. S.; Vieira, V. P. P. B.; Diniz, L. S.; Lacerda, E. G. M.; Carvalho, A. C. P. L. F; Ludermir, T. B. Sistemas inteligentes: Aplicações a recursos hídricos e ciências ambientais. Porto Alegre: UFRGS/ABRH, 1999. 246p.

Hagan, M. T.; Menhaj, M. B. Training feedforward networks with the Marquardt algorithm. IEEE Transactions on Neural Networks, v.5, n.6, p.989-993, 1994.

Hargreaves, G. H.; Samani, Z. Reference crop evapotranspiration from ambient air temperature, Chicago: American Society Agricultural Engineering Meeting, 1985 (Paper 85-2517).

Haykin, S. Redes Neurais: Princípios e prática. 2.ed. Porto Alegre: Bookman, 2001. 900p.

Kovács, Z. L. Redes neurais artificiais: Fundamentos e aplicações. 3.ed. São Paulo: Livraria da Física, 2002. 174p.

Kumar, M.; Raghuwanshi, N. S.; Singh, R.; Wallender, W. W.; Pruitt, W. O. Estimating evapotranspiration using artificial neural network. Journal of Irrigation and Drainage Engineering, v.128, n.4, p.224-233, 2002.

Odhiambo, L. O.; Yoder, R. E.; Yoder, D. C.; Hines, J. W. Optimization of fuzzy evapotranspiration model through neural training with input-output examples. Transactions of the ASAE, v.44, n.6, p.1625-1633, 2001.

Pereira, A. R.; Angelocci, L. R.; Sentelhas, P. C. Agrometeorologia: Fundamentos e aplicações práticas. Guaíba: Agropecuária, 2002. 478p.

Samani, Z. Estimating solar radiation and evapotranspiration using minimum climatological data. Journal of Irrigation and Drainage Engineering, v.126, n.4, p.265-267, 2000.

Silva, A. F. Previsão da evapotranspiração de referência utilizando redes neurais. Viçosa: UFV, 2002. 68p. Dissertação Mestrado

Soares, P. P. S.; Nadal, J. Aplicação de uma rede neural feedforward com algoritmo de Levenberg-Marquardt para classificação do segmento ST do eletrocardiograma. In: Congresso Brasileiro de Redes Neurais, 4, 1999, São José dos Campos. Anais... São José dos Campos: ITA, 1999, p.384-389. 
Sudheer, K. P.; Gosain, A. K.; Ramasastri, K. S. Estimating actual evapotranspiration from limited climatic data using neural computing technique. Journal of Irrigation and Drainage Engineering, v.129, n.3, p.214-218, 2003.

Trajkovic, S.; Todorovic, B.; Stankovic, M. Forecasting of Reference Evapotrans-piration by Artificial Neural Networks. Journal of Irrigation and Drainage Engineering, v.129, n.6, p.454-457, 2003.
Willmott, C. J. On the validation of model. Physical Geography, v.2, n.2, p.184-194, 1981.

Zanetti, S. S.; Sousa, E. F.; Oliveira, V. P. S.; Almeida, F. T.; Bernardo, S. Estimating evapotranspiration using artificial neural network and minimum climatological data. Journal of Irrigation and Drainage Engineering, v.33, n.2, p.83-89, 2007. 